\title{
Characterization of CdTe Growth on GaAs Using Different Etching Techniques
}

\author{
E. BILGILISOY ${ }^{10},{ }^{1,2,3}$ S. ÖZDEN,${ }^{1}$ E. BAKALI,${ }^{1}$ M. KARAKAYA, ${ }^{1}$ \\ and Y. SELAMET ${ }^{1}$
}

1.-Department of Physics, Izmir Institute of Technology, Urla, 35430 Izmir, Turkey. 2.-e-mail: bilgilisoy.elif@gmail.com. 3.—e-mail: elifbilgilisoy@iyte.edu.tr

\begin{abstract}
CdTe buffer layers which were grown on (211)B GaAs by molecular beam epitaxy were subjected to two different etch treatments to quantify the crystal quality and dislocation density. The optical properties and thicknesses of the samples were obtained by ex situ spectroscopic ellipsometry. The surface morphologies of the CdTe epilayers were analyzed by atomic force microscopy, scanning electron microscopy, and Nomarski microscopy before and after chemical etching. We compare the triangle- and trapezoid-shaped etch pits due to the Everson and Nakagawa etch solutions, respectively. Measured etch pit density (EPD) values of triangle etch pits were found in the $8 \times 10^{7} \mathrm{~cm}^{-2}$ to $2 \times 10^{8} \mathrm{~cm}^{-2}$ range, and trapezoid-shaped etch pits were found in the $1 \times 10^{7} \mathrm{~cm}^{-2}$ to $7 \times 10^{7} \mathrm{~cm}^{-2}$ range for samples with thicknesses $<2 \mu \mathrm{m}$.
\end{abstract}

Key words: Defect decoration etching, molecular beam epitaxy, CdTe, etch pit density, spectroscopic ellipsometry, Raman mapping

\section{INTRODUCTION}

$\mathrm{HgCdTe}$ is one of the most important infrared (IR) detector materials. No other material system yet offers comparable performance for strategic applications. However, difficulties associated with suitable substrates prevent large-format focal-plane arrays. The lattice-matched substrate, CdZnTe (with $4 \% \mathrm{Zn}$ ), has some issues. Besides being extremely expensive, it has large thermal mismatch with Si readout integrated circuits (ROICs) and is a very brittle material. ${ }^{1}$ On the other hand, alternative substrates have been widely studied especially for molecular beam epitaxy (MBE) growth of HgCdTe. ${ }^{2}$ Among these, Si and GaAs are the most promising, with tremendous progress having been made in recent years. ${ }^{3,4}$ They are low cost and large area, and have many fewer surface defects compared with CdZnTe. Surface dislocation density values of $\mathrm{Si}, \mathrm{GaAs}$, and $\mathrm{CdZnTe}$ substrates are $\sim 100 \mathrm{~cm}^{-2}, \sim 10^{3} \mathrm{~cm}^{-2}$, and $\sim 10^{4} \mathrm{~cm}^{-2}$, respectively. ${ }^{5}$ However, there exists a large lattice parameter

(Received December 20, 2014; accepted April 30, 2015; published online June 10, 2015) difference between $\mathrm{HgCdTe}$ and alternative substrates. To minimize the deleterious effects of the large lattice mismatch between the alternative substrates such as $\mathrm{Si}, \mathrm{Ge}$, and $\mathrm{GaAs}$ and the epilayer, $\mathrm{HgCdTe}$ needs to be grown on a buffer layer including CdTe or CdZnTe. ${ }^{6,7}$ This lattice mismatch leads to a large number of misfit dislocations in the epilayer. Most of these dislocations propagate into the growing film from the substrate interface. Surface defects of the buffer layer reduce the detector and focal-plane array performance ${ }^{8}$ of the $\mathrm{HgCdTe}$ epilayers grown on them. Hence, the crystal quality and dislocation density of CdTe grown on an alternative substrate needs to be analyzed for high-performance $\mathrm{HgCdTe}$ infrared devices.

Wet chemical defect decoration etching is the commonest process to reveal various kinds of defects, especially those related to dislocations. Different etch techniques leave different pit shapes on the surface. Decoration etching creates etch pits at the end points of dislocations terminating at the surface due to the difference in bond strength. In addition, crystal symmetry along the direction perpendicular to the surface can be monitored by the shape of the etch pits. ${ }^{9}$ 
The Everson ${ }^{10}$ and Nakagawa ${ }^{11}$ etches are used as standard etch pit density methods for CdTe materials. It has been reported that, for use on CdTe, the Nakagawa etching solution is effective only for the (111)A crystal orientation. ${ }^{12,13}$ Everson et al. proposed an etchant solution to reveal dislocations on CdTe in both (111)B and (211)B orientations. Since then, Everson etching has become the most commonly used characterization technique for B face of CdTe. ${ }^{10}$

In this work, we utilized two different etch methods of Nakagawa and Everson on CdTe (211)B epilayers with expectedly high structural defect content grown on GaAs to reveal and obtain the areal density of defects related to dislocations and/or other defect types. We compared and analyzed the Everson (triangle-like shaped pits) and Nakagawa (trapezoid-like shaped pits) etch pit density results from CdTe samples grown under different growth conditions. Atomic force microscopy (AFM), Nomarski microscopy, scanning electron microscopy (SEM), and Raman spectroscopy were used to characterize the etching effects.

\section{EXPERIMENTAL PROCEDURES}

CdTe buffer layers were grown on $20 \mathrm{~mm} \times$ $20 \mathrm{~mm}$ epiready GaAs (211)B substrates cut from 4-inch wafers using a Veeco GEN20MZ MBE

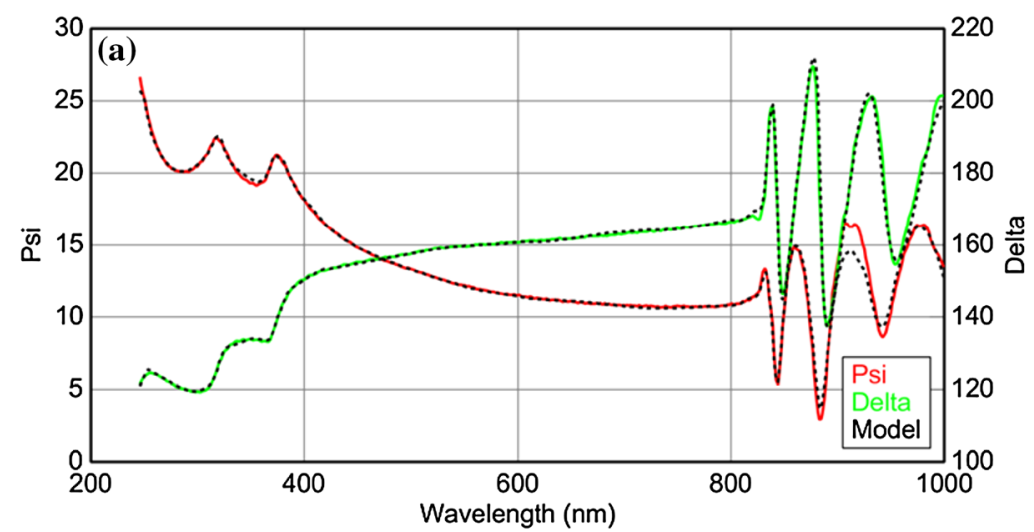

\begin{tabular}{|c|c|c|c|c|c|}
\hline (b) Sample \# & MSE & $\begin{array}{c}\text { Thickness } \\
\text { Oxide }(\mathrm{nm})\end{array}$ & $\begin{array}{c}\text { Thickness } \\
\text { CdTe }(\mathrm{nm})\end{array}$ & $\begin{array}{c}\text { Band Gap } \\
(\mathrm{eV})\end{array}$ & $\begin{array}{c}\mathrm{n} \text { of CdTe @ } \\
1.240 \mathrm{eV}\end{array}$ \\
\hline 1 & 8.84 & 2.96 & 1926.29 & 1.51 & 2.92 \\
\hline
\end{tabular}

Fig. 1. Ex situ SE (a) model and experimental data of psi and delta versus wavelength and (b) measurement results of as grown sample 1.

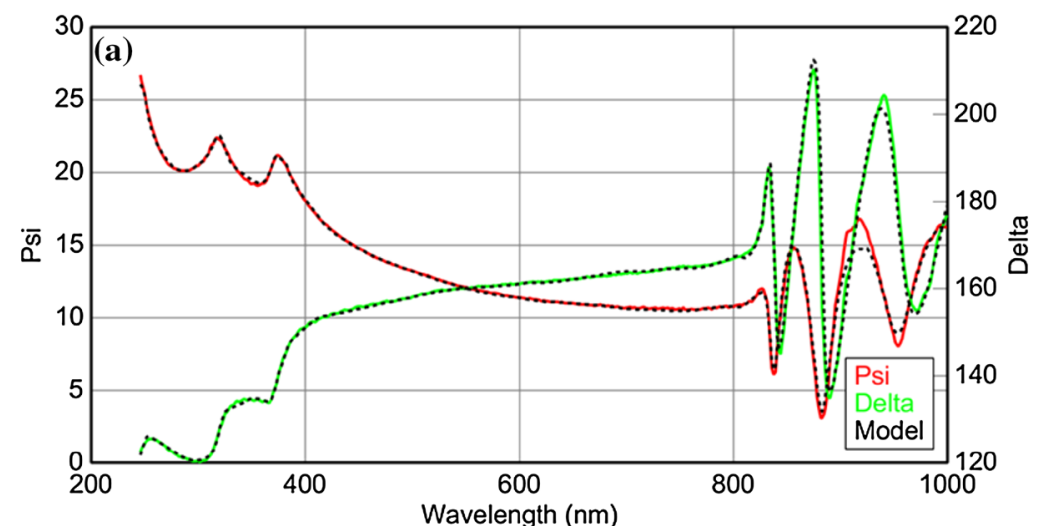

\begin{tabular}{|c|c|c|c|c|c|}
\hline (b) & MSE & $\begin{array}{c}\text { Thickness } \\
\text { Oxide }(\mathrm{nm})\end{array}$ & $\begin{array}{c}\text { Thickness } \\
\text { CdTe }(\mathrm{nm})\end{array}$ & $\begin{array}{c}\text { Band Gap } \\
(\mathrm{eV})\end{array}$ & $\begin{array}{c}\mathrm{n} \text { of CdTe @ } \\
1.240 \mathrm{eV}\end{array}$ \\
\hline 2 & 9.19 & 2.50 & 1628.58 & 1.51 & 2.93 \\
\hline
\end{tabular}

Fig. 2. Ex situ SE (a) model and experimental data of psi and delta versus wavelength and (b) measurement results of sample 2 . 
Table I. Defect decoration methods, volume ratios, etching times, and EPD values for samples 1 and 2

\begin{tabular}{|c|c|c|c|c|c|}
\hline Sample \# & Etch method & & Volume ratio & Etch time (s) & $\operatorname{EPD}\left(\mathrm{cm}^{-2}\right)$ \\
\hline \multirow[t]{6}{*}{1} & \multirow[t]{4}{*}{ Everson $\left(\mathrm{C}_{2} \mathrm{H}_{4} \mathrm{OHCOOH}: \mathrm{HNO}_{3}: \mathrm{HF}\right)$} & E1 & $25: 4: 1$ & 15 & $7.9 \times 10^{7}$ \\
\hline & & $\mathrm{E} 2$ & $25: 4: 2$ & 15 & $9.3 \times 10^{7}$ \\
\hline & & E3 & $25: 8: 1$ & 20 & NA \\
\hline & & $\mathrm{E} 4 *$ & $25: 4: 0.5$ & 20 & $8.6 \times 10^{7}$ \\
\hline & \multirow[t]{2}{*}{ Nakagawa $\left(\mathrm{H}_{2} \mathrm{O}: \mathrm{H}_{2} \mathrm{O}_{2}: \mathrm{HF}\right)$} & N1 & $20: 20: 30$ & 20 & NA \\
\hline & & $\mathrm{N} 2 *$ & & 7 & $1.4 \times 10^{7}$ \\
\hline \multirow[t]{6}{*}{2} & \multirow[t]{4}{*}{ Everson $\left(\mathrm{C}_{2} \mathrm{H}_{4} \mathrm{OHCOOH}: \mathrm{HNO}_{3}: \mathrm{HF}\right)$} & $\mathrm{E} 1 *$ & $25: 4: 1$ & 15 & $1.4 \times 10^{8}$ \\
\hline & & $\mathrm{E} 2$ & $25: 4: 2$ & 15 & NA \\
\hline & & $\mathrm{E} 4$ & $25: 4: 0.5$ & 15 & $8.3 \times 10^{7}$ \\
\hline & & E6 & $25: 4: 1$ & 10 & $1.8 \times 10^{8}$ \\
\hline & \multirow[t]{2}{*}{ Nakagawa $\left(\mathrm{H}_{2} \mathrm{O}: \mathrm{H}_{2} \mathrm{O}_{2}: \mathrm{HF}\right)$} & $\mathrm{N} 2 *$ & $20: 20: 30$ & 7 & $4.8 \times 10^{7}$ \\
\hline & & N3 & & 5 & $6.5 \times 10^{7}$ \\
\hline
\end{tabular}

*The etch techniques of SEM images of samples are given in Fig. 6.
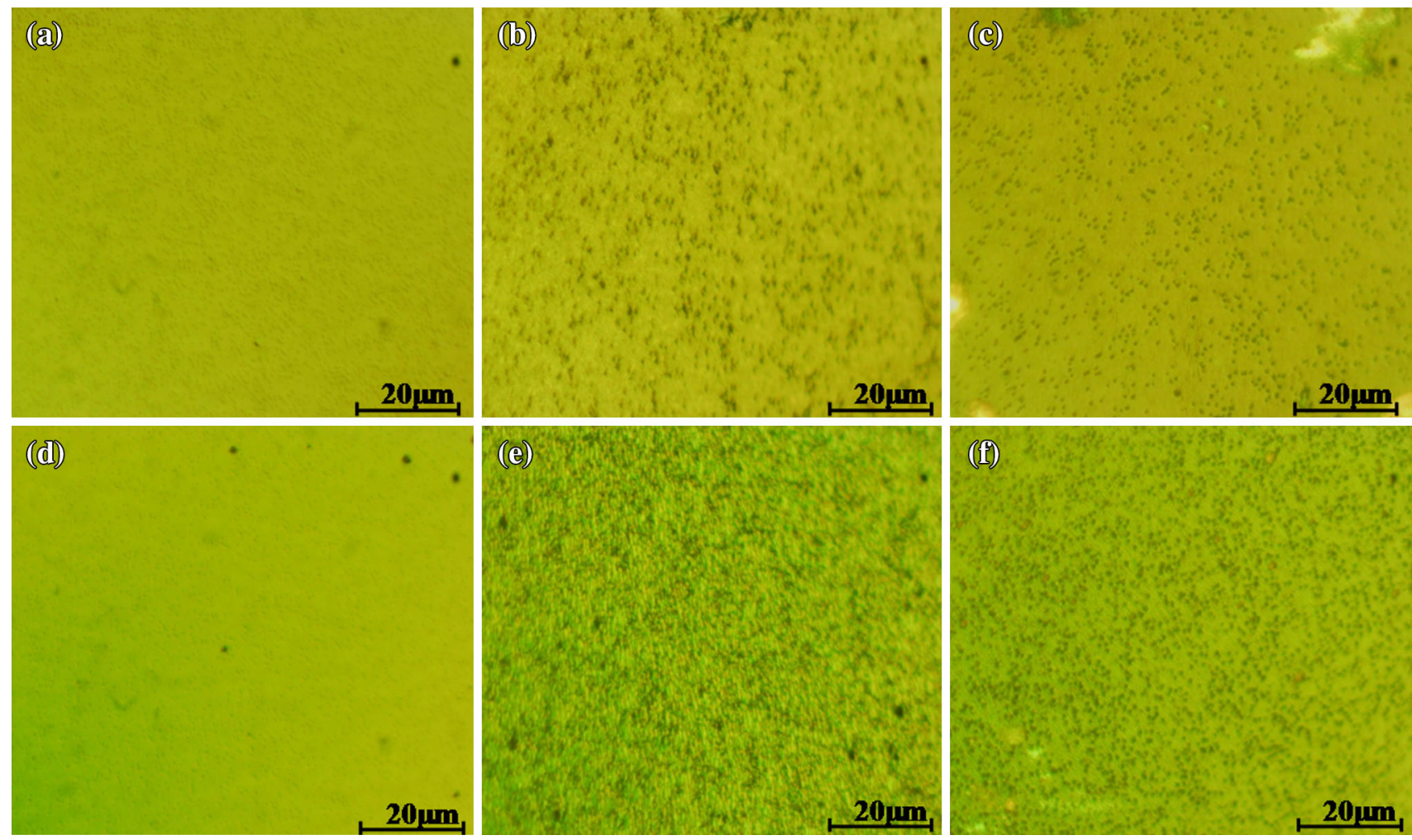

Fig. 3. Nomarski microscopy images of sample 1 (a) as grown, (b) after 1 E4 etch, and (c) after 1 N2 etch, and sample 2 (d) as-grown, (e) after $2 \mathrm{E} 4$ etch, and (f) after $2 \mathrm{~N} 2$ etch, at $\times 100$ magnification.

system. The GaAs native oxide was desorbed at $586^{\circ} \mathrm{C}$ for 4 min under $\mathrm{As}_{4}$ flux. After this step, the substrate temperature was cooled to $280^{\circ} \mathrm{C}$ and $250^{\circ} \mathrm{C}$ to grow a $\mathrm{CdTe}$ (sample 1 and sample 2 , respectively) nucleation layer. Finally, the substrate temperature was increased to the growth temperature of $300^{\circ} \mathrm{C}$ under $\mathrm{Te}_{2}$ flux and the growth was carried at a rate of about $1 \mu \mathrm{m} / \mathrm{h}$.

A Woollam model M-2000X ellipsometer was used for epilayer optical constant and thickness measurements. The Woollam library was used in the determination of epilayer thicknesses. The photon energy range of the ellipsometer was $1.24 \mathrm{eV}$ to $5.00 \mathrm{eV}$. This range was divided into 470 wavelengths. A xenon arc lamp was used as a light source. The transmittance of CdTe films was measured at room temperature in the range from $4000 \mathrm{~cm}^{-1}$ to $15,500 \mathrm{~cm}^{-1}$ using a Bruker Vertex-80v spectrometer equipped with a roomtemperature InGaAs detector and $\mathrm{KBr}$ windows. During measurements, a green laser with wavelength of $532 \mathrm{~nm}$ was used. Thicknesses of CdTe layers were also obtained from intensity oscillations in the transmittance spectra. 

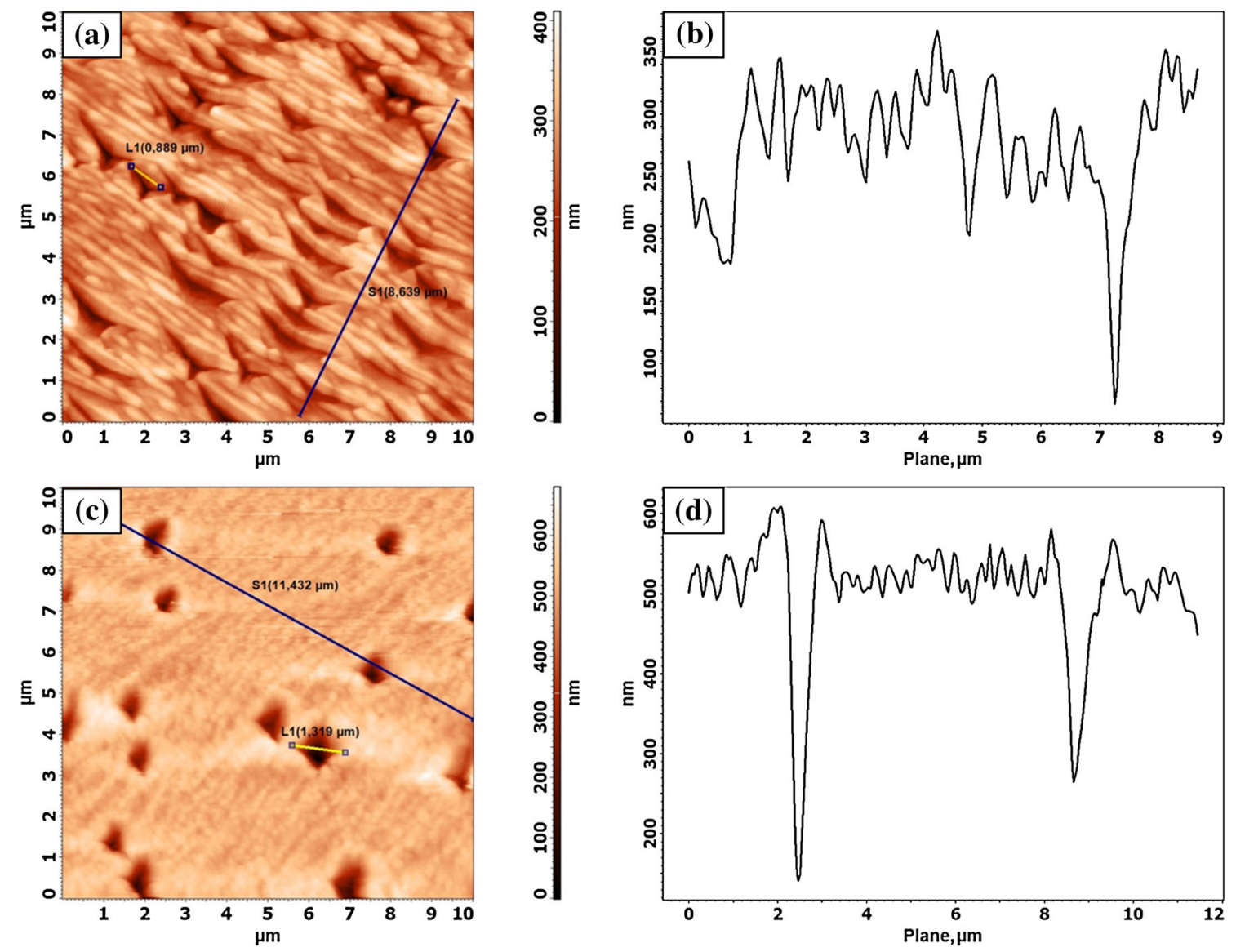

Fig. 4. Sample 1 AFM 2D topographical images: $(a, b)$ length analysis and cross-section line analysis of pits after 1E4 etch; (c, d) length analysis and cross-section line analysis of pits after 1N2 etch.

As-grown CdTe samples were diced into several pieces and standard EPD methods applied. Etching times were kept shorter than the usual etching times to prevent overlapping of pits for accurate EPD measurements. We focused our investigation on two different etch methods: Everson and Nakagawa. It has been reported that Nakagawa etching is effective only for (111)A crystal orientation. ${ }^{12}$ To apply the etching procedures, Everson $\left(\mathrm{C}_{2} \mathrm{H}_{4} \mathrm{OH}-\right.$ $\left.\mathrm{COOH}: \mathrm{HNO}_{3}: \mathrm{HF}\right)$ and Nakagawa $\left(\mathrm{H}_{2} \mathrm{O}: \mathrm{H}_{2} \mathrm{O}_{2}: \mathrm{HF}\right)$ etch solutions were prepared with various volume ratios in polypropylene beakers at room temperature. The chemical reaction taking place during etch pit formation consists of steps of oxidation and dissolution of the oxide, with the volume ratios of the constituents of the etching solution determining the rate of each process. Therefore, we tried different volume ratios of these etchants to adjust the etch rate on CdTe (211)B samples. For etching, a diced piece of the sample was dipped into these mixtures with gentle stirring at room temperature. The samples were rinsed in deionized (DI) water and dried with high-purity $\mathrm{N}_{2}$. The etch pits were then observed using differential interference contrast (DIC) microscopy (also known as Nomarski microscopy) at $\times 100$ magnification and $\mathrm{AFM}$ in semicontact mode. The widths and depths of the etch pits were measured by using AFM length and cross-section analysis tools. The areal density of etch pits was obtained by both manual counting and a software program $^{14}$ from the AFM and SEM images.

To investigate the effects of the wet chemical etching procedures on Te, CdTe, and GaAs vibrational modes, two-dimensional $(x, y)$ maps were recorded by Raman spectroscopy at room temperature. Raman measurements were performed by a confocal Raman system using an $\mathrm{Ar}^{+}$-ion 488-nm excitation laser with maximum radiation power of $120 \mathrm{~mW}$ with a $700-\mathrm{mm}$-focal-length grating spectrometer at $1800 \mathrm{gr} / \mathrm{mm}$ grating. The light was directed onto the sample using a $\times 100$ objective, and Raman scattered light was detected by an In$\mathrm{GaAs}$ detector with resolution of $0.3 \mathrm{~cm}^{-1}$.

\section{RESULTS AND DISCUSSION}

To measure the epilayer thickness, we performed spectroscopic ellipsometry (SE) and Fourier-transform infrared (FTIR) transmittance measurements. The SE results showed that the CdTe epilayer thickness was approximately $1.9 \mu \mathrm{m}$ and $1.6 \mu \mathrm{m}$ 

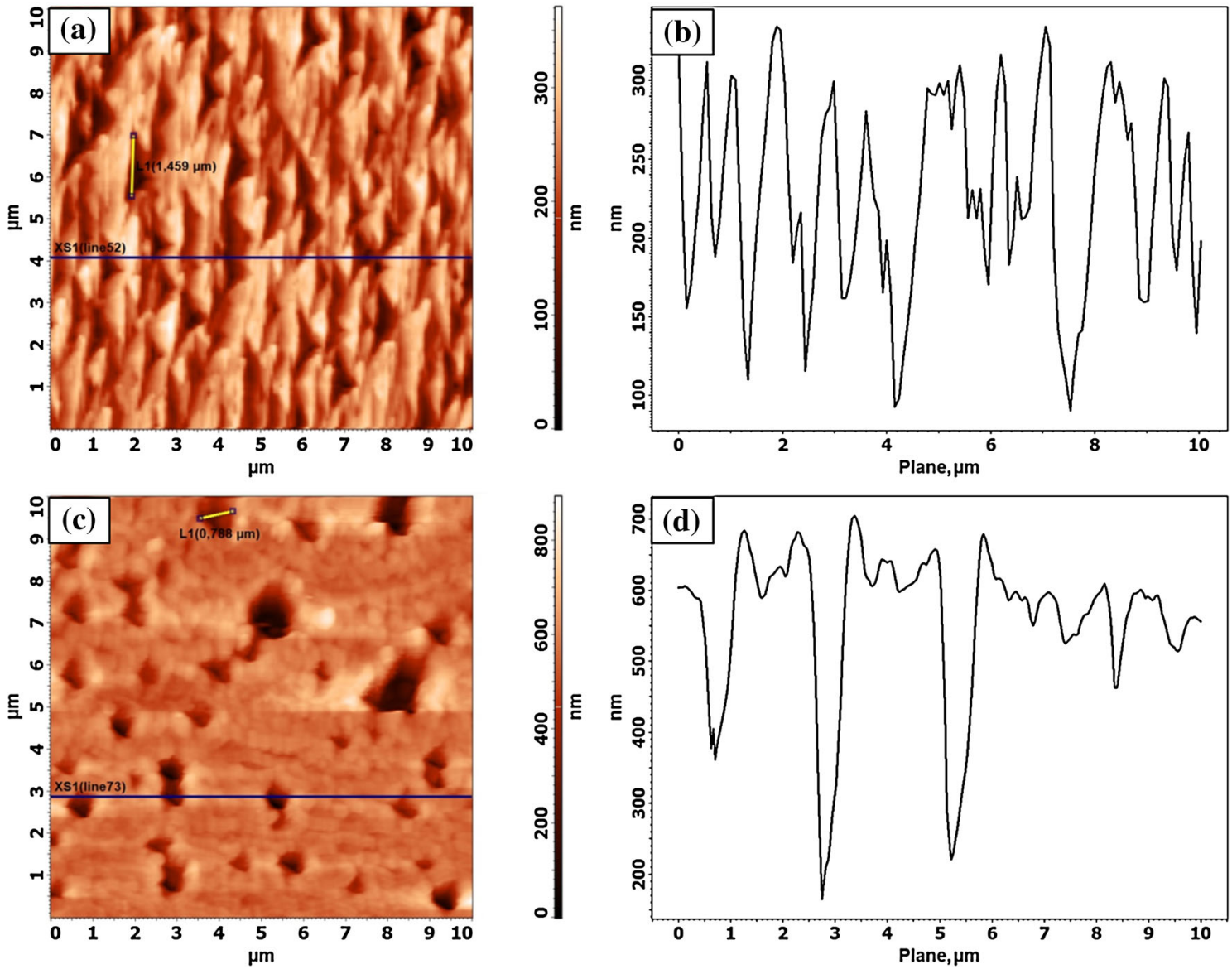

Fig. 5. Sample 2 AFM 2D topographical images: $(a, b)$ length analysis and cross-section line analysis of pits after 2E1; (c, d) length analysis and cross-section line analysis of pits after $2 \mathrm{~N} 2$ etch.

(Figs. 1 and 2). To obtain the thickness, the ellipsometric data were fit using a model with three layers: GaAs substrate, CdTe film, and a surface oxide layer. The Cauchy material CdTe-oxide was used as a surface layer. For the substrate, the dielectric function for GaAs in the Woollam library was used. In this optical model, general oscillators were used to construct the CdTe dielectric function. Oxide thicknesses and CdTe thicknesses were obtained using this optical model for each sample. CdTe thicknesses were obtained as $2.1 \mu \mathrm{m}$ and $1.7 \mu \mathrm{m}$ for sample 1 and 2 , respectively, from FTIR transmittance, being comparable to the SE measurements. Thicknesses of nucleation layers for sample 1 and 2 were $<100 \mathrm{~nm}$.

Table I presents the etching methods, volume ratios of etching solutions, etch times, and EPD values for two epilayers studied. The results obtained from the Everson and Nakagawa etching were examined for both samples by using different surface characterization methods. EPD results indicated that decreasing the application time of the etchant in both techniques led to a slight increase in the EPD values. This might be due to overlapping of enlarged pits to a larger pit for longer etching. It was shown that the etch pit size depended on the etching implementation time and solution volume ratios. It can also be seen from this table that the EPD results for sample 2 were higher than those for sample 1 . This might be the result of differences in growth conditions.

Nomarski microscopy was used to determine the as-grown epilayer surface topography (Fig. 3a and d) and surface morphology changes after the Everson etch (Fig. 3b and e) and Nakagawa etch (Fig. 3c and f). The pits were not fully resolved for sample 1 and sample 2, respectively, at magnification of $\times 100$. Therefore, we did not attempt to count defects to establish their areal density from these images. On the other hand, the relative concentration of the defects from these images was clear enough for comparison. The first sample had a relatively defectfree as-grown surface (Fig. 3a). Everson etching produced larger pits compared with Nakagawa etching on this sample. The same was also true for the second sample. The second sample had more defects on the as-grown surface compared with the first sample. Etch pits produced by the Nakagawa method were better resolved in Nomarski images than those produced by the Everson method.

AFM $10 \mu \mathrm{m} \times 10 \mu \mathrm{m}$ topographic images, pit width, and cross-section line analysis on these 

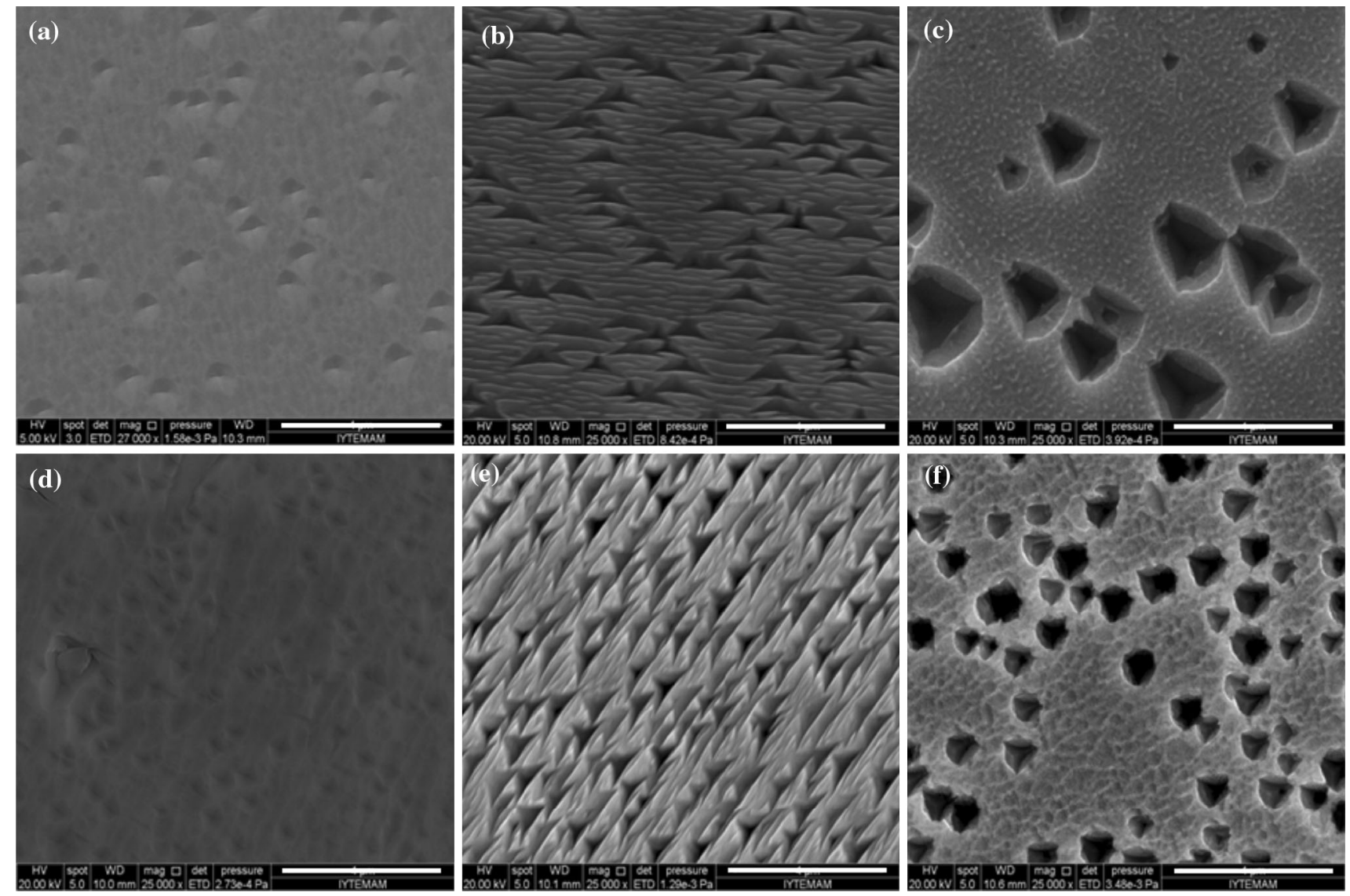

Fig. 6. SEM images of (a) as-grown surface of sample 1, (b) after 1E4 etched sample, (c) after the 1N2, (d) as-grown surface of sample 2, (e) after 2E1 etched sample, and (f) after 2N2 (all scale bars are $4 \mu \mathrm{m}$ ).

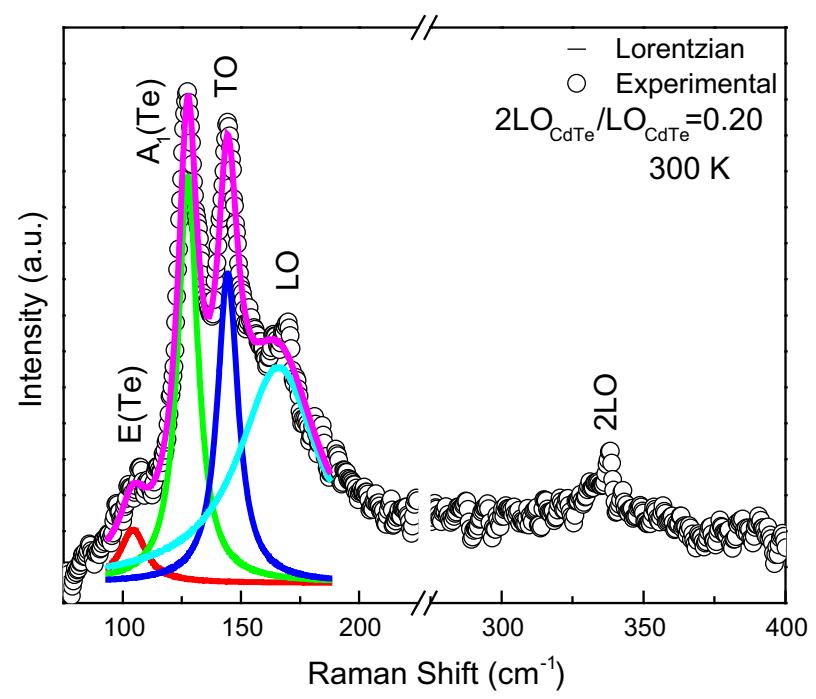

Fig. 7. Raman scattering spectrum of as-grown sample 2. images for sample 1 are shown in Fig. 4. In this figure it can be seen that 1E4-etched sample 1 has well-defined triangular etch pits on the surface (Fig. 4a). The average size of these pits was about $0.9 \mu \mathrm{m}$, and the average depth was about $260 \mathrm{~nm}$. Figure 4c shows the 1N2 etch pits formed on sample 1. These etch pits had about $1.3 \mu \mathrm{m}$ average size and about $360 \mathrm{~nm}$ average depth (Fig. 4d). From Fig. $4 \mathrm{a}$ and c, EPD values were counted as $\sim 7.3 \times$ $10^{7} \mathrm{~cm}^{-2}$ for $1 \mathrm{E} 4$ and $\sim 1.5 \times 10^{7} \mathrm{~cm}^{-2}$ for $1 \mathrm{~N} 2$.

In Fig. 5, the AFM topography images of $2 \mathrm{E} 1$ and 2N2 etch pits for sample 2 indicate that the $2 \mathrm{E} 1$ method creates "triangular" pits with average size of $\sim 1.5 \mu \mathrm{m}$ and average depth of $\sim 245 \mathrm{~nm}$ on the sample. Similar to the other sample, the $2 \mathrm{~N} 2$ etch reveals etch pits (Fig. 5c), having $\sim 0.8 \mu \mathrm{m}$ average size and $\sim 420 \mathrm{~nm}$ average depth. From Fig. 5a and c, EPD values were found to be $\sim 8.4 \times 10^{7} \mathrm{~cm}^{-2}$ for $2 \mathrm{E} 1$ and $\sim 4.1 \times 10^{7} \mathrm{~cm}^{-2}$ for $2 \mathrm{~N} 2$. 
Table II. Representative peak positions of phonon modes of as-grown sample 1 and 2

\begin{tabular}{|c|c|c|c|c|c|}
\hline $\begin{array}{l}\text { As-Grown } \\
\text { Sample \# }\end{array}$ & $\begin{array}{c}\text { Te-Specific } \\
\text { E }\left(\mathrm{cm}^{-1}\right)\end{array}$ & $\begin{array}{c}\text { Te-Specific } \\
\mathbf{A}_{1}\left(\mathbf{c m}^{-1}\right)\end{array}$ & $\begin{array}{c}\text { TO of } \\
\operatorname{CdTe}\left(\mathrm{cm}^{-1}\right)\end{array}$ & $\begin{array}{c}\text { LO of } \\
\operatorname{CdTe}\left(\mathrm{cm}^{-1}\right)\end{array}$ & $\begin{array}{c}\text { 2LO of } \\
\operatorname{CdTe}\left(\mathrm{cm}^{-1}\right)\end{array}$ \\
\hline Sample 1 & $10 \overline{4} .3$ & $\begin{array}{l}126.8 \\
127.5\end{array}$ & 145.5 & 169.4 & 337.8 \\
\hline
\end{tabular}
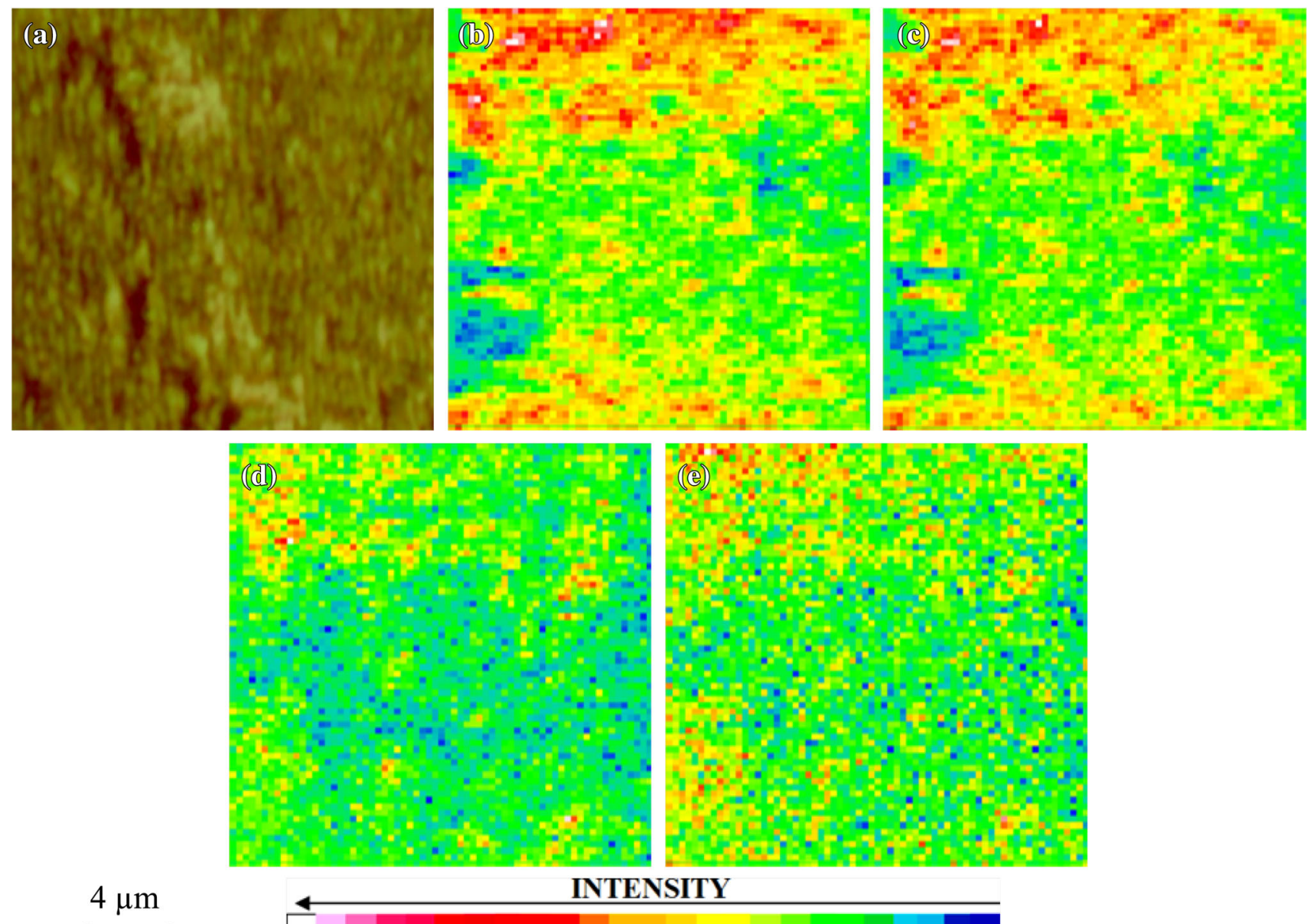

INTENSITY

Fig. 8. (a) Optical microscope image of $20 \mu \mathrm{m} \times 20 \mu \mathrm{m}$ scanned area on 1E4-etched sample. Raman intensity change of (b) $\mathrm{A}_{1}$-symmetry mode of Te, (c) CdTe-like TO phonon mode, (d) CdTe-like LO phonon mode, and (e) GaAs-like TO phonon mode.

As-grown surface defects which are related to growth conditions for sample 1 and 2 can be seen clearly in Fig. 6a and d, respectively. "Triangular" shape pits on the surface after the Everson etch are also seen in SEM images (Fig. 6b and e). Furthermore, the Nakagawa-etched samples had "trapezoid-like" pits, and they were aligned in the same orientation (Fig. 6c and f). EPD values obtained by manual and software ${ }^{14}$ counting from SEM images (Fig. 6) were in agreement with each other. Table I gives the EPD results from SEM images of the samples. EPD values obtained from AFM images are in good agreement with those obtained from SEM images. Everson etching with $\mathrm{HF}: \mathrm{HNO}_{3}$ : $\mathrm{C}_{2} \mathrm{H}_{4} \mathrm{OHCOOH}$ (1:4:25) volume ratio is an industry standard for characterization of B side of CdTe. However, as stated above, Nakagawa etch was reported to produce pits only for (111)A face but not for either (111)B or (211)B face. ${ }^{10}$ However, there exist some reports claiming production of etch pits for B face of CdTe. Nakagawa et al. indicated that Nakagawa solution revealed dislocations on $\mathrm{CdTe}$ (111)B but not on CdTe (111)A. ${ }^{11}$ Another study also reported that Nakagawa solution with different chemical variations worked on B face of CdTe. ${ }^{15}$ Everson etch yields good estimation of dislocation density. However, Nakagawa etch results correlate well with the as-grown surface defect density. We thinned down the samples with several $\mathrm{Br}_{2}-\mathrm{MeOH}$ polishing steps. EPD after each step was almost 

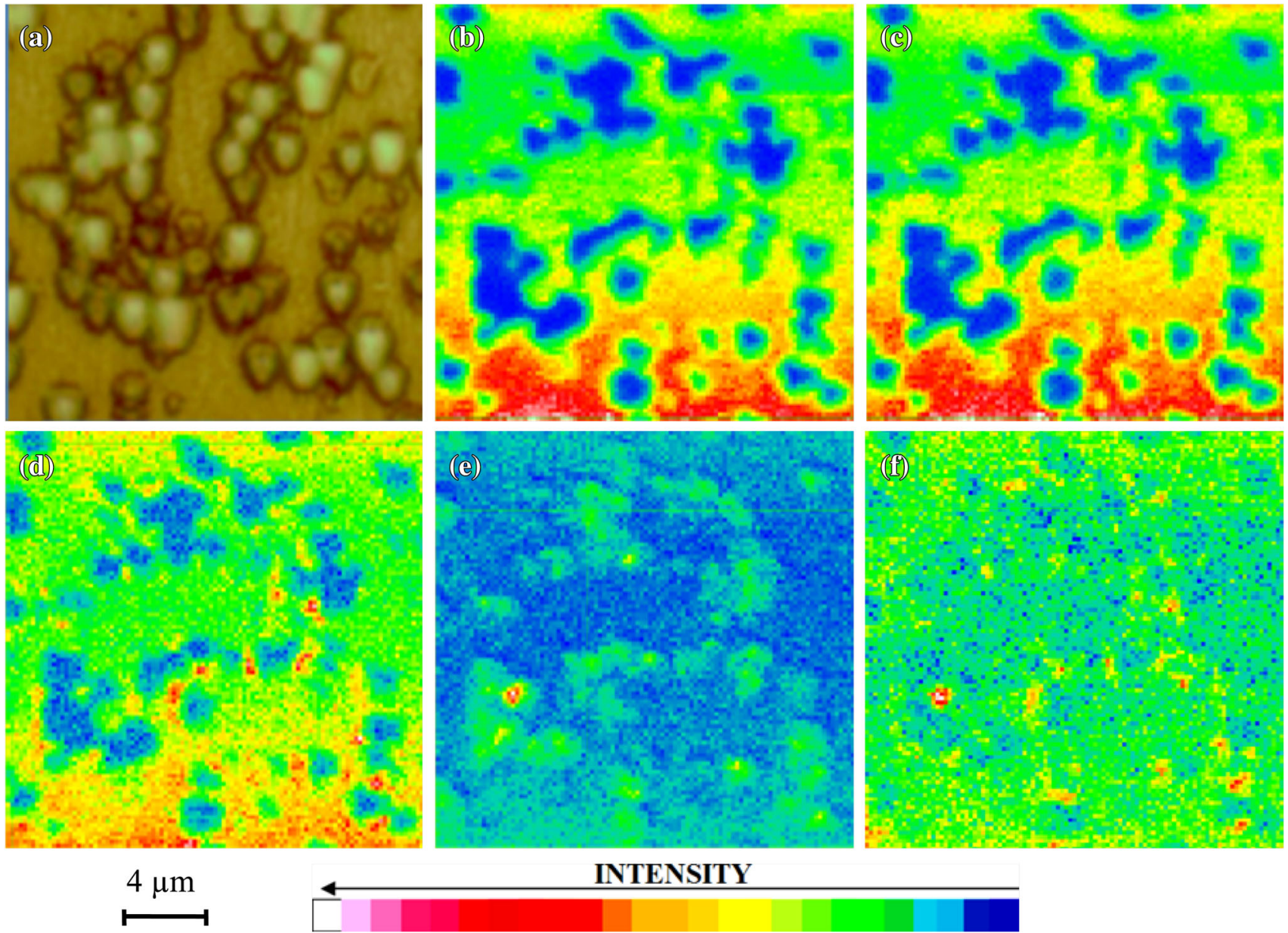

INTENSITY

Fig. 9. (a) Optical microscope image of $20 \mu \mathrm{m} \times 20 \mu \mathrm{m}$ scanned area on 1N2-etched sample. Raman intensity change of (b) $\mathrm{A}_{1}$-symmetry mode of Te, (c) CdTe-like TO phonon mode, (d) CdTe-like LO phonon mode, (e) GaAs-like TO phonon mode, and (f) GaAs-like LO phonon mode.

Table III. Raman intensity distribution of phonon modes of etched sample 1 and 2

\begin{tabular}{|c|c|c|c|c|c|}
\hline $\begin{array}{l}\text { Etched } \\
\text { Sample \# }\end{array}$ & $\begin{array}{c}\text { Te-Specific } \\
\mathbf{A}_{1}\left(\mathrm{~cm}^{-1}\right)\end{array}$ & $\begin{array}{c}\text { TO of } \\
\operatorname{CdTe}\left(\mathrm{cm}^{-1}\right)\end{array}$ & $\begin{array}{c}\text { LO of } \\
\operatorname{CdTe}\left(\mathrm{cm}^{-1}\right)\end{array}$ & $\begin{array}{c}\text { TO of } \\
\operatorname{GaAs}\left(\mathrm{cm}^{-1}\right)\end{array}$ & $\begin{array}{c}\text { LO of } \\
\operatorname{GaAs}\left(\mathrm{cm}^{-1}\right)\end{array}$ \\
\hline $1 \mathrm{E} 4$ & 123.8 & 142.4 & 170.8 & 275.5 & - \\
\hline $1 \mathrm{~N} 2$ & 123.8 & 140.9 & 169.4 & 269.8 & 293.6 \\
\hline $2 \mathrm{E} 1$ & 125.3 & 131.5 & 170.8 & 268.4 & - \\
\hline $2 \mathrm{~N} 2$ & 122.4 & 142.4 & 170.9 & 265.5 & - \\
\hline
\end{tabular}

constant. This means the as-grown surface defects were not due to substrate oxide removal before the growth, but were related to growth conditions. ${ }^{1}$ The triangular- and trapezoid-like shapes of the etch pits are due to preferential etching in some certain crystal orientations.

The two main Raman-active modes in zincblende CdTe are transverse optical (TO) and longitudinal optical (LO) phonon modes at the Brillouin zone center $(\Gamma)$. The TO and LO phonon modes of CdTe occur at approximately $141 \mathrm{~cm}^{-1}$ and $168 \mathrm{~cm}^{-1}$, respectively. ${ }^{16}$ Additional peaks have been reported at $92 \mathrm{~cm}^{-1}, 103 \mathrm{~cm}^{-1}, 120 \mathrm{~cm}^{-1}$, and $147 \mathrm{~cm}^{-1}$ with $\mathrm{A}_{1}$ and $\mathrm{E}$ symmetry modes of Te due to the presence of Te precipitates in CdTe. ${ }^{17}$ For the samples studied here, TO, LO, and 2LO phonon modes of CdTe were observed at $145.5 \mathrm{~cm}^{-1}, 169.4 \mathrm{~cm}^{-1}$, and $337.8 \mathrm{~cm}^{-1}$ for as-grown sample 1 . In addition to these CdTe phonon modes, a Te-specific $\mathrm{A}_{1}$ phonon mode was acquired at $126.8 \mathrm{~cm}^{-1}$. For as-grown sample 2, CdTe TO, LO, and $2 \mathrm{LO}$ phonon modes were obtained at $144.4 \mathrm{~cm}^{-1}, 165.8 \mathrm{~cm}^{-1}$, and $336.0 \mathrm{~cm}^{-1}$. Te-specific $\mathrm{A}_{1}$ and $\mathrm{E}$ phonon modes were also obtained at $104.3 \mathrm{~cm}^{-1}$ and $127.5 \mathrm{~cm}^{-1}$ 
(Fig. 7). Raman spectroscopy phonon modes for as-grown samples are presented in Table II. The Raman intensity variation over a $20 \mu \mathrm{m} \times 20 \mu \mathrm{m}$ area for 1E4 is shown in Fig. 8. The Raman mapping technique was performed on an Everson-etched (1E4) sample with $0.3-\mu \mathrm{m}$ step size with $67 \times 67$ spectra being collected to form the maps. The following Raman peaks were obtained: TO and LO phonon modes of CdTe at $142.4 \mathrm{~cm}^{-1}$ and 170.8 $\mathrm{cm}^{-1}$, respectively. There was also a peak at $123.8 \mathrm{~cm}^{-1}$, indicating the presence of Te precipitates. Furthermore, a weak TO phonon mode of GaAs was observed at $275.4 \mathrm{~cm}^{-1}$ at some locations, indicating the depth of the pits. As can be seen from the Raman intensity maps, the distribution of the $\mathrm{A}_{1}$-symmetry mode of Te and CdTe TO phonon mode resemble each other, with etched darker areas having lower intensities of $\mathrm{A}_{1}$-symmetry mode and CdTe-like TO phonon mode. In addition, in some regions (e.g., upper and lower sides of the map area), Raman intensities of $A_{1}$-symmetry mode of Te and TO phonon mode of CdTe were higher, which might be a result of thickness variation due to an artifact of the etching process. Additionally, the CdTe-like LO phonon mode intensity was lower compared with the TO phonon mode intensity. Moreover, higher GaAs TO phonon mode intensities were observed at locations where weaker CdTe phonon mode intensities were observed. This indicates that these areas were pit locations.

Raman intensity distributions of CdTe-like, Te-like, and GaAs-like phonon modes for 1N2etched sample are shown in Fig. 9. The Raman mapping was obtained from a $20 \mu \mathrm{m} \times 20 \mu \mathrm{m}$ area with $0.2-\mu \mathrm{m}$ steps and Raman spectra collected from $101 \times 101$ points. CdTe-like TO and LO phonon modes were obtained at $140.9 \mathrm{~cm}^{-1}$ and 169.4 $\mathrm{cm}^{-1}$. Unlike the other measurements, both Raman-active TO and LO phonon modes of GaAs were observed from these measurements, at $269.8 \mathrm{~cm}^{-1}$ and $293.6 \mathrm{~cm}^{-1}$, respectively. Etch pits were clearly observed in both optical and Raman intensity variation images of Te-, CdTe-, and GaAs-related phonon modes. Moreover, higher GaAs TO phonon mode intensities were observed at locations where weaker CdTe phonon mode intensities were observed. This indicates that these areas were pit locations. The intensity of TO phonon mode of GaAs was higher for deeply etched areas (Fig. 9e). However, the LO phonon mode of GaAs was distributed more homogeneously, exhibiting mostly higher intensities on the scanned area compared with the GaAs-like TO phonon mode intensity distribution (Fig. 9f). At some points, the GaAs phonon mode intensities were very high compared with the rest of the surface. These points might correspond to etch pits extending all the way to the substrate.

Raman intensity distributions of CdTe-like, Te-like, and GaAs-like phonon modes for etched sample 1 and 2 are summarized in Table III.

\section{CONCLUSIONS}

It was indicated that the etch pit size depended on the etching implementation time and solution volume ratios. Decreasing the etching implementation time in both etching techniques led to a slight increase in EPD values. This might be due to overlapping of enlarged etch pits with increasing etching time to a larger pit, hence leading to undercounting.

Everson etching produced triangular- while Nakagawa etching produced trapezoid-shaped pits on the CdTe (211)B surface, and the pits were all aligned in the same direction. Everson etching gives good estimation of dislocation density, and changing the volume ratios did not affect the EPD values. Comparing the as-grown and after-etch defect densities, it was inferred that the Nakagawa etch enlarged and etched as-grown surface defects in certain crystal orientations. Therefore, Nakagawa etching can be used to reveal some specific growthrelated defects.

The Raman intensity distributions show that, after the decoration methods were performed, the intensities of $\mathrm{A}_{1}$-symmetry mode of Te, and CdTe-like TO and LO phonon modes decreased, but GaAs-like TO phonon mode intensities were increased on triangular and trapezoid shapes. Moreover, CdTe-like LO phonon mode and GaAs-like TO phonon mode intensities were lower compared with $\mathrm{A}_{1}$-symmetry and CdTe-like TO phonon mode Raman intensities. Te-specific $\mathrm{E}_{1}$-symmetry mode was clearly observable before but not after both etching methods.

\section{ACKNOWLEDGEMENTS}

This study has been supported by the Gediz Project at Izmir Institute of Technology. The authors would like to thank Hasan Aydın, Begum Yavas, and Sinem Duman for their assistance in taking atomic force microscopy, ex situ spectroscopic ellipsometer, and Raman mapping measurements. Use of facilities at the IZTECH Material Research Center for scanning electron microscopy is acknowledged.

\section{REFERENCES}

1. L. He, X. Fu, Q. Wei, W. Wang, L. Chen, Y. Wu, X. Hu, J. Yang, Q. Zhang, and R. Ding, J. Electron. Mater. 37, 1189 (2008).

2. J. Benson, L. Bubulac, P. Smith, R. Jacobs, J. Markunas, M. Jaime-Vasquez, L. Almeida, A. Stoltz, J. Arias, and G. Brill, J. Electron. Mater. 41, 2971 (2012).

3. L. He, L. Chen, Y. Wu, X. Fu, Y. Wang, J. Wu, M. Yu, J. Yang, R. Ding, and X. Hu, J. Cryst. Growth 301, 268 (2007).

4. R. Jacobs, C. Nozaki, L. Almeida, M. Jaime-Vasquez, C. Lennon, J. Markunas, D. Benson, P. Smith, W. Zhao, and D. Smith, J. Electron. Mater. 41, 2707 (2012).

5. R. Jacobs, L. Almeida, J. Markunas, J. Pellegrino, M. Groenert, M. Jaime-Vasquez, N. Mahadik, C. Andrews, S. Qadri, and T. Lee, J. Electron. Mater. 37, 1480 (2008).

6. S. Johnson, J. Vigil, J. James, C. Cockrum, W. Konkel, M. Kalisher, R. Risser, T. Tung, W. Hamilton, and W. Ahlgren, J. Electron. Mater. 22, 835 (1993). 
7. S. Johnson, T. De Lyon, C. Cockrum, W. Hamilton, T. Tung, F. Gesswein, B. Baumgratz, L. Ruzicka, O. Wu, and J. Roth, J. Electron. Mater. 24, 467 (1995).

8. S.M. Johnson, D. Rhiger, J. Rosbeck, J. Peterson, S. Taylor, and M. Boyd, J. Vac. Sci. Technol. B 10, 1499 (1992).

9. S. Farrell, M.V. Rao, G. Brill, Y. Chen, P. Wijewarnasuriya, N. Dhar, D. Benson, and K. Harris, J. Electron. Mater. 40, 1727 (2011).

10. W. Everson, C. Ard, J. Sepich, B. Dean, G. Neugebauer, and H. Schaake, J. Electron. Mater. 24, 505 (1995).
11. K. Nakagawa, K. Maeda, and S. Takeuchi, Appl. Phys. Lett. 34, 574 (1979).

12. P. Fewster and P. Whiffin, J. Appl. Phys. 54, 4668 (1983).

13. Y. Jianrong, G. Huiming, C. Xinqiang, F. Weizheng, and H. Li, J. Cryst. Growth 234, 337 (2002).

14. http://imagej.nih.gov/ij/. Accessed April 13, 2015.

15. R. Bagai, G. Mohan, G. Seth, and W. Borle, J. Cryst. Growth 85, 386 (1987)

16. P. Amirtharaj and F.H. Pollak, Appl. Phys. Lett. 45, 789 (1984).

17. R. Zitter, Surf. Sci. 28, 335 (1971). 